\title{
Psychosocial Impacts of Covid 19 Pandemic in Zimbabwe
}

\author{
Never Pavari \\ College of Peace, Leadership, and governance, Africa University, Zimbabwe \\ E-mail: pastorpavari@yahoo.co.uk
}

Received: Jun. 14, 2020 Accepted: Aug. 26, 2020 Online published: Sept. 13, 2020

doi:10.5296/jpag.v10i3.17687ＵRL: https://doi.org/10.5296/jpag.v10i3.17687

\begin{abstract}
The Covid-19 pandemic has continued to cause socio-economic damages which will take a long time to recover from while there is no vaccine in sight. The impacts are affecting the social well-being of global citizens which triggers the need to investigate the psychosocial effects. In order to achieve and to provide the missing African context, the study was done in Zimbabwe. Due to lockdown restrictions, samples were obtained using online survey and social media platforms. Analysis was done to determine the effects, so far, of the virus on the general economy, psychological and social aspects as well as religious values of the citizens qualitatively and quantitatively. The findings indicated that economic loses were recorded at household, corporate and national levels. Indicators included increases in prices and exchange rate which eroded the buying power of local currency and increased the cost of basic commodities. Economic pressures, Covid-19 trends and restrictions imposed caused psychological damages which included fear, feeling of uncertainty and loss of hope. The study recommended increased awareness and psychological support to help the citizens to overcome mental displeasures. The study has potential to assist policy makers, health practitioners and development partners in developing strategies to eliminate Covid-19 related psychosocial pressures in Zimbabwe and globally.
\end{abstract}

Keywords: corona virus, psychological, lockdown, pandemic, income, social impact

\section{Introduction}

The Corona virus commenced its effects by first cases which were registered in Wuhan in Hubei Province of China in December 2019 (Gao, Tian, \& Yang, 2020; Singh \& Adhikari, 2020; Torales et al., 2020). There are varied opinions regarding the origin of the virus with some attempting to connect it with open meat markets in Wuhan China (Ho et al., 2020). This, however, has been strongly refuted by the Chinese Government who point the origin of the virus to natural causes. Recently, the World Health Organization has weighed in and 
attributed the virus to natural causes. Other have labelled the virus as a biological warfare between super powers while others have even associated it with economic sabotage efforts which failed in aim to isolate China. Although the origins may need further discussions, the impacts the virus have so far caused have been felt globally regardless of economic strength and development status of affected nations. The virus is highly transmissible and spread such as by inhaling air contaminated by an infected person, contact with infected person and with objects and surface on which the virus has landed from an infected person (Dong, Du, \& Gardner, 2020; Torales et al., 2020). The virus has also not spared medical practitioners some of whom were infected resulting in closure of some hospitals and deaths in some cases (Ahmed et al., 2020; Shaw, 2020; Torales et al., 2020). The virus affects the respiratory system causing breathing difficulties resulting in death in extreme cases. The effects of the virus have ranged from mild to severe with extreme cases requiring hospitalization and support systems to aid breathing (CDC COVID-19 Response Team., 2020; Dong et al., 2020; Hellewell, 2020). Unfortunately, in most cases, infections have overtaken capacities of hospitals in both developing and developed countries. The virus has been spreading to all continents causing huge economic loses, social distress and loss of lives.

Impacts were initially marked by massive deaths which were recorded in Wuhan followed by economic lockdown in attempts to slow down the spread of the virus through social distancing. Traveling between China and other countries and between countries continued even after lives were lost in Wuhan due to the virus (Ahmed et al., 2020). The virus went on to affect other countries with highest numbers of mortality recorded in United States, Italy and then in Brazil. By end of May 2020, the number of deaths from Covid-19 had exceeded 150000 in the United States of America despite lockdown efforts. In Latin America news were heard about dead bodies which were found lying in the streets as the virus continued its torture. Increasing number of cases were also recorded in Africa with high number of infections and deaths in South Africa and Egypt by end of May 2020. Globally, countries were faced with the debate on whether to open industries for business to save economies. Attempts by some countries to re-open business were faced by increases in the number of new infections which worsened decision making. In Zimbabwe, the number of cases was stable between recording of first cases in March and May 2020 when cases plummeted due to returnees into the country from countries with high infection records. Although returnees were quarantined, once in their country, they require medical attention and change infection statistics depending on their status. The biggest challenge surrounding Covid-19 was absence of vaccine to control the virus while it is deadly. In most developing countries, the virus poses a great threat given limited resources and ill equipped hospitals which cannot accommodate scenarios experienced in developed countries.

The virus has broadly caused extreme psychosocial pressures which have affected even the wealthiest global strata. For example, experience or knowledge of resultant massive deaths with no known vaccine available has become a great source of uncertainty among global citizens (CDC COVID-19 Response Team., 2020; Goodell, 2020; Remuzzi \& Remuzzi, 2020). A lot of restrictions have also been imposed on citizens by governments which has placed lifestyles far from the norms. As a result of lockdowns most global citizens are faced 
with potential losses of employment and other sources of income which disrupt well-being (Hellewell, 2020; Lau et al., 2020; Qiu et al., 2020; Zhang, 2020). In most countries, lockdown was implemented in stages with some stages disallowing most regular interactions. In addition, people were introduced to very odd practices such as wearing of face masks and avoiding handshakes which are strange in their usual culture. While the solution to Covid-19 is still out of sight, it is important to understand in depth its psychosocial impacts (Flahault, 2020; Qiu et al., 2020; Singh \& Adhikari, 2020). Although some impacts are global, a national or even more local perspective is useful for tailored solutions. More specifically, trends in developing countries need close monitoring given that they already cannot handle pre-existing pressure on which the effects of Covid-19 are superimposed. However, since the virus first affected China, most studies on its impacts on mental and social wellness of people were mostly done in this country (Ahmed et al., 2020; Cao et al., 2020; Lau et al., 2020; Qiu et al., 2020; Zhang, 2020; Zheng, 2020) leaving out other developing countries especially in Africa. For example, Zimbabwe has been struggling to ensure stable economic growth, has serious foreign currency shortages and has not yet even recovered fully from the impacts of Cyclone Idai which caused huge socio-economic losses in her eastern districts. Definitely, impacts of Covid-19 in such an economy needs to be understand especially in effort to reduce pressure on the poorest in such countries.

In view of the above, the study sought to understand the psychosocial impacts of Covid-19 in Zimbabwe, in Southern Africa. The study investigates the psychological, social and economic (general) responses to the pandemic in the developing country. Analysis will include on effect of the pandemic on religious values as well as lessons learnt in response to the Covid-19.

\section{Methodology}

\subsection{Description of Study Area}

Zimbabwe is located in Southern Africa with an estimated population of 13572560 according to the 2017 Inter Censal Demographic Survey (Zimbabwe National Statistics Agency., 2017). The survey also showed that the age-sex population distribution of Zimbabwe presents a pyramid with narrow top and broad base. Over the past decades economic growth has been slow in the country which has compromised livelihoods and health service delivery in the country. Owing to difficult operating conditions, some of the industries have closed over the years while those still in business are operating below capacity. Most of the basic amenities are beyond the reach of ordinary citizens. In March 2020, Zimbabwe recorded its first Covid-19 case with the infected person passing on a few days later. The country implemented restrictions including heavy lockdown between end of March and early May which successfully kept infection levels at their lowest. Up to mid-May the total number of infections was below 50 but increased to above 150 due to relaxation of lockdown rules, opening of other businesses and returnees from high infection countries. Increases in infections were mostly attributed to returnees who were quarantined upon arrival for 21 days. A few cases were reported of some individuals who fled quarantine centres increasing risk of infecting others who have been observing rules set by the government. Due to phased relaxation of lockdown rules, a significant number of citizens were still restricted 
and did not possess letters to travel around cities beyond $5 \mathrm{~km}$. Figure 1 shows number of Covid-19 cases recorded from 20 March to 31 May per province in Zimbabwe. By the end of May, the highest number of Covid-19 cases had been recorded in Harare (87) followed by Masvingo (27) and Matebeleland South (18).

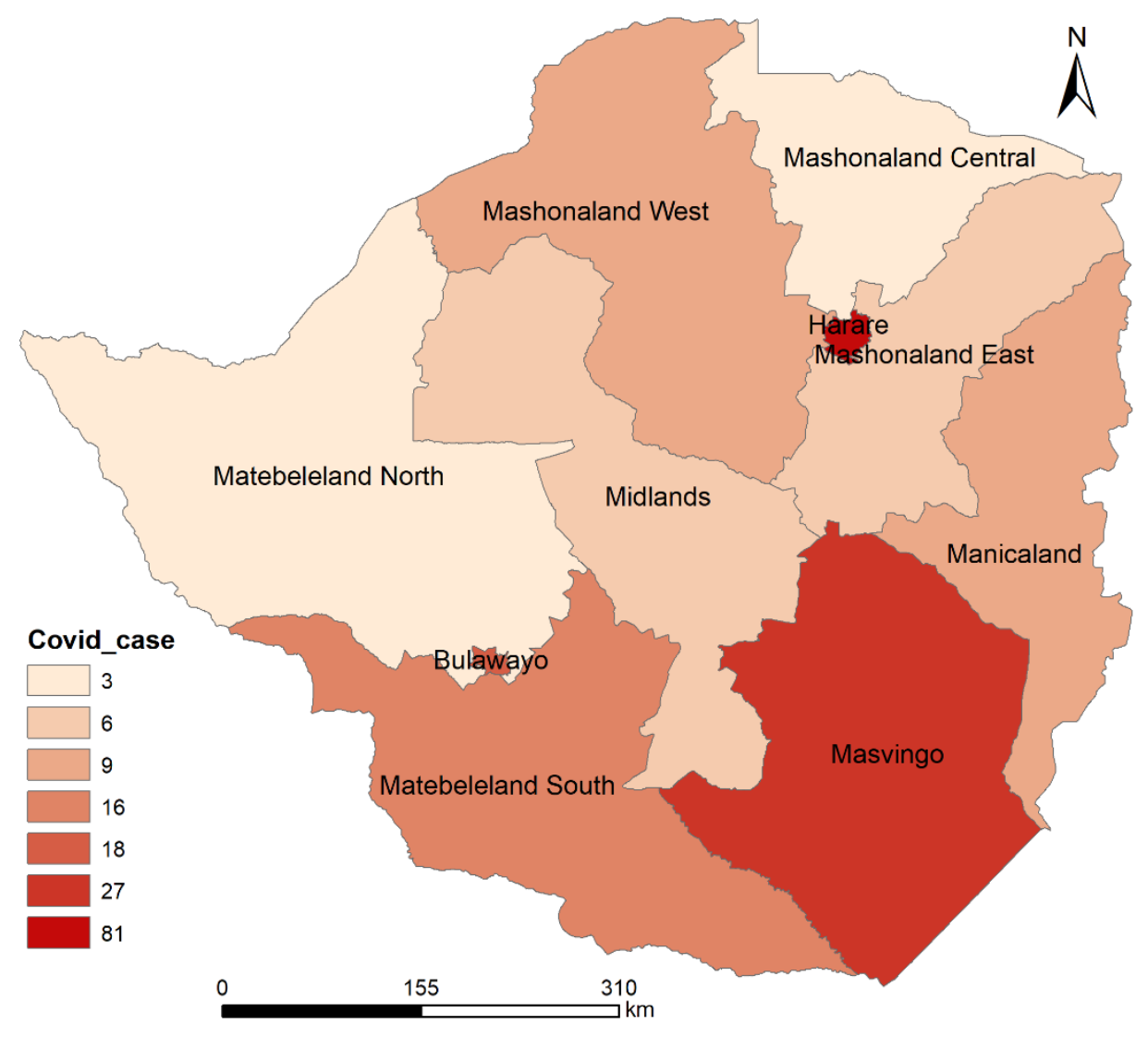

\subsection{Data Collection and Analysis Procedure}

The study blended qualitative with quantitative research designs. The quantitative was used to provide visible statistical measures of the impacts while the qualitative aspect provided opinions based on experiences of the communities as they interfaced with the Covid-19 pandemic. In order to obtain data from the target population a questionnaire was designed. The questionnaire lured information such as general extent of economic loss, social impacts, psychological impacts and impacts on traditional/religious values. The questionnaire also probed for lessons learnt from the experiences of Covid-19. The study was conducted when lockdown rules were still in force in Zimbabwe. This made it not viable to visit any community to avoid breaking social distancing rules while it was largely impossible to travel beyond $50 \mathrm{~km}$. On the other hand, social media and online platform had capacity to break most of the limitations and still allow data to be collected. Therefore, the questionnaire was sent around using social media platforms which included WhatsApp, Twitter and Facebook. The questionnaire was also sent to some using e-mail although this only gave access to the researcher's network of contacts only. In order to reach out to even more, an online questionnaire was designed in Survey Monkey website (www.surveymonkey.com) and a link was generated. The link was also shared in social media platforms while the responses were 
automatically collected as respondents filled in. Online surveys and social media were also used to assess impacts of Covid-19 in China (Wang et al., 2020; Ahmed et al., 2020) which motivated the same approach in this study.

A total of 637 questionnaires were completed and, fortunately, each respondent completed all questions. Although, a larger sample size was desired, the number of responses could provide a picture of experiences in the country. Ahmed et al., (2020) used a sample size of 1074 in while Wang et al., (2020) collected responses from 1304 people in China. Given that the research was conducted during the lockdown period and very small population size of Zimbabwe compared to China, the sample size used in this study was meaningful. All the responses were checked for quality and consistence before use in any analysis. The data collected using questionnaires were sorted to allow in depth and thorough analysis of each objective qualitatively and quantitatively. The data for quantitative aspects were coded to allow computation of frequencies, tabulation and plotting of graphs.

\section{Results}

\subsection{Characterization of Respondents}

The large proportion of responses (67\%) came from Harare which was viewed as an advantage given that it is the capital city of Zimbabwe and had so far recorded the highest number of Covid-19 cases. The respondents were not stratified by gender or age but by current involvement ranging from school going (secondary/high school) to those employed or running businesses. Primary school pupils were not included for ethical to avoid infringing their rights by bombarding them with questions and in view that they may largely be immature to provide reliable information. The greatest proportion of respondents were in the formally employed strata while the least proportion were the unemployed group. Since the survey relied on data bundles for accessing social media and internet platforms, the criteria may have excluded the unemployed due to limited resources.

Table 1. Characteristics and distribution of respondents

\begin{tabular}{lc}
\hline Characteristic & Proportion of total number of respondents \\
\hline Attending secondary/high school & $6.3 \%$ \\
Attending college & $6.3 \%$ \\
Unemployed/school leavers & $3.1 \%$ \\
Formally employed & $65.6 \%$ \\
Informally employed & $12.5 \%$ \\
Others & $15.6 \%$ \\
\hline
\end{tabular}

\subsection{Economic Impacts of Covid 19}

The lockdown and restrictions imposed to control the spread of the corona virus largely affected business operations and income generation activities of most respondents. The reduction in economic activities as well as complete shutdown in most of the cases resulted in loss of income at all levels of operation. More than $50 \%$ of respondents indicated that they lost income by more than $60 \%$ while $91 \%$ experienced at least some loss $(>0 \%)$ due to the 
pandemic (Figure 2). This affected both the owners and employees in formal and informal lines of business. The economy of Zimbabwe is largely informal and these were worst affected because relaxation of lockdown rules with time did not give them chance to resume normal operations. Some respondents cited that their consultancy activities were slowed down as field data collection was halted during lockdown which also reduced their income. Even where businesses had opened levels of transaction were still low especially those that needed physical visit of clients. Traveling into Central Business Districts and industrial areas was restricted lowering direct transactions in those areas. Other businesses were strongly impacted with low chances of resuming. One of the respondents indicated that their "small business of selling fish which had become a source of livelihood was closed due to Covid-19 as it was an informal setup". However, there were other industries that fell in categories which were allowed to operate while exercising great caution.

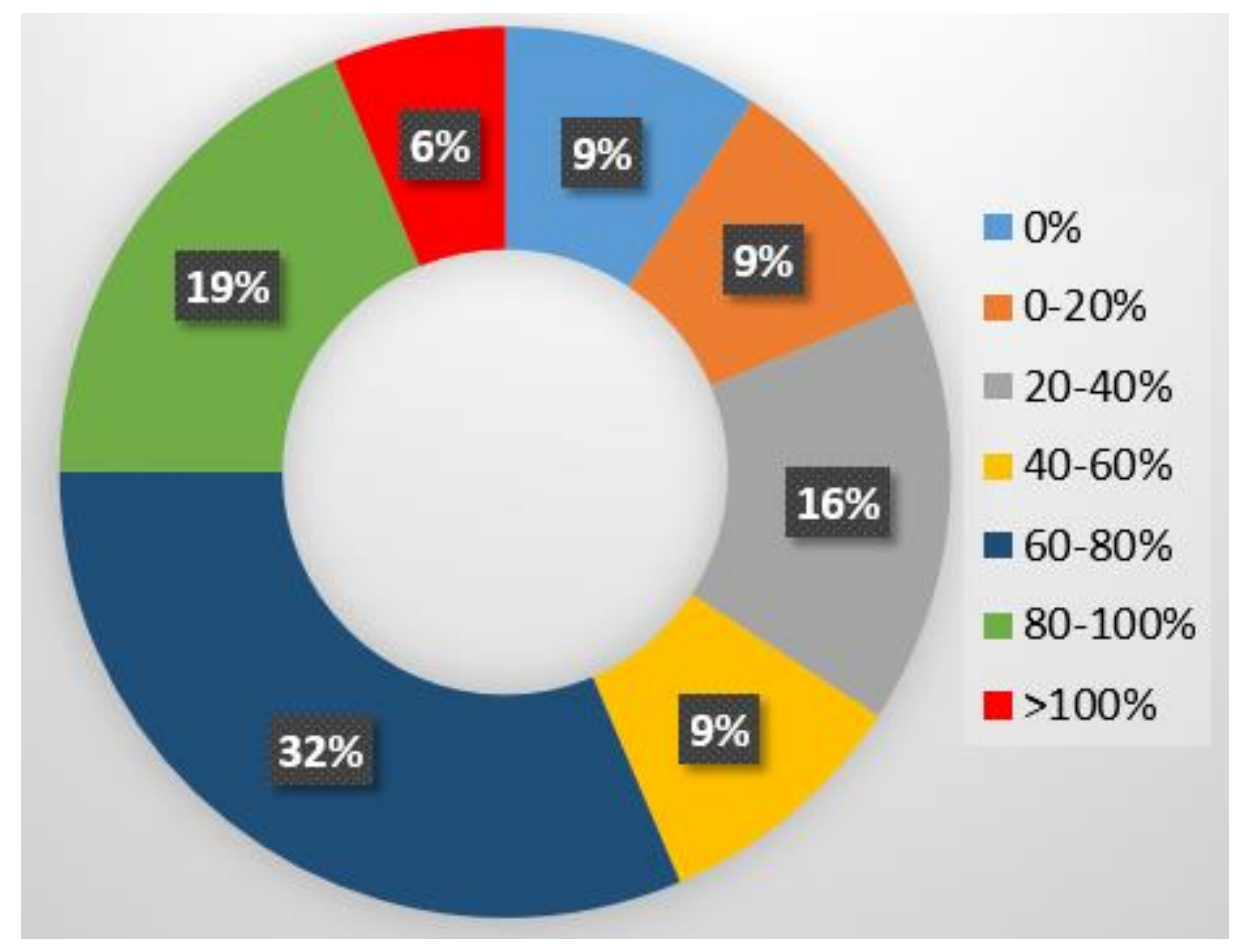

Figure 2. Economic losses from Covid-19

Some of the respondents indicated that the products they sell are very sensitive to the income of their target market. Since most their clients lost their capacity to earn income and they are living on savings, they are not keen to use available resources for any other things than basic needs. For others, their products and services require marketing through direct interaction with potential clients which was not possible due to lockdown rules. Most industries in Zimbabwe were not operating on their full capacity even before the pandemic. As a result, some of the respondents survive from cross border trading bringing goods from neighbouring and other countries for selling in the country. Traveling restrictions due to the pandemic resulted in some completely becoming unable to import the goods while others resorted to alternatives such as paying truck driver to bring for them at very high costs. This forced them to increase prices of goods for the local market. Exchange rates were changing rapidly during 


\section{Macrothink}

the lockdown period which eroded the value of the local currency and further triggered price hikes beyond the reach of most ordinary citizens especially those earning local currency and those depending on savings.

Ordinary citizens also felt the economic pinch due to the pandemic. Most respondents indicated that they were forced to use savings which earmarked for other personal development purposes. Other indicated that they had saving in powerful foreign currencies which they were forced to use as the local currency continued to lose value with local earnings not able to match the cost of daily basic needs. Others who rely on donations were negatively impacted as their sources were not yet open for business or were still experiencing down turn in business. The church was also not spared as members especially those in the informal business sectors could not make any payments due to economic pressure. Other respondents expressed that they experienced "serious salary cuts" while prices of basic goods and services were rising. For example, one of the respondents stressed that "due to loss of income, if a family member is sick we can't afford to send to hospital". However, while most of the respondents experienced losses due to the pandemic, 34\% of the respondents indicated that they registered at least some gain in income due to the pandemic (Figure 3). A very small proportion $(3 \%)$ indicated that they recorded more $100 \%$ increase in income despite the lockdown.

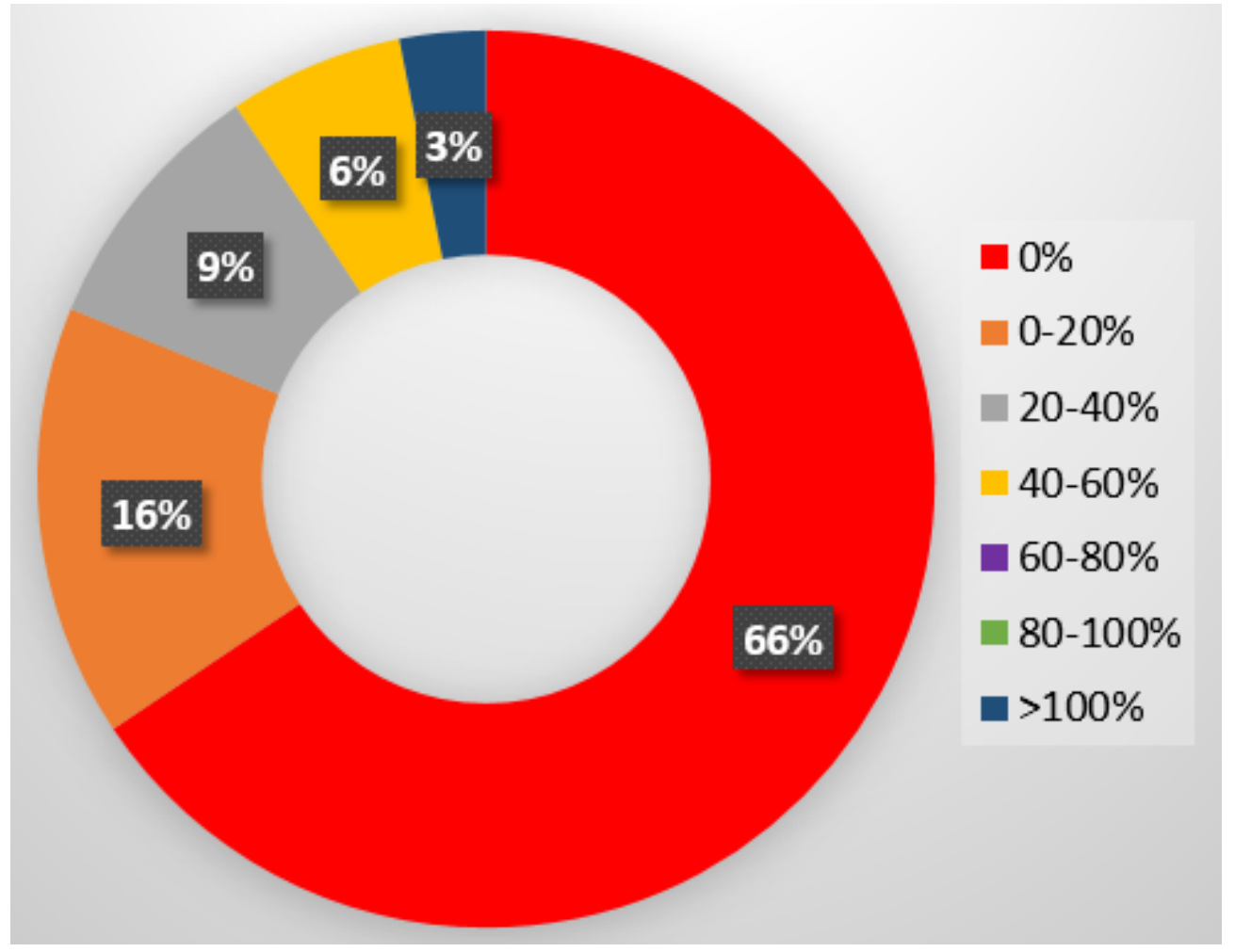

Figure 2. Percentage gain from COvid-19 pandemic

\subsection{Social Impacts}

On a positive note, lockdown awarded citizens time to spend time with their immediate families. This gave families time to reconnect, bond and finding each other without 
disruptions which normally occur with busy schedules caused by work and businesses. For others, the lockdown caused a period of social isolation and loneliness due to inability to be with friends and extended family. The situation was even more stressful in cases where some members of the family are outside the country for school or work purposes. One of the parents whose child is studying in South Africa was depressed by the separation due to travel restriction and the experience of the child going through the tough phase without parental guidance. In response to effects of social distancing, one responded expressed that "God created us unique, we are social beings and the mere fact that we can't interact with all of our relationships has negatively affected us". There were lamentations caused by failure to meet the responsibility of visiting parents and extended families in rural areas while they connect to culture. Those who depend on assistance from others indicated that the lockdown could not allow them to mingle with their helpers which deprived them of potential support during the period.

Economic constraints caused by lockdown allowed other respondents the social responsibility of assisting relatives and friends who became financially, psychologically and socially unstable. Loss of income and hikes in prices of basic commodities were reported to have caused food insufficiency and family squabbles in some cases. Another group of respondents indicated the frustration they had after cancelling events amidst the pandemic. Gatherings were banned after they had spent financial and other resources on preparations. Events affected included graduation ceremonies and weddings which could not be held under social distancing rules. Although some universities went on to perform virtual graduation ceremonies, some of the respondents aired that this did not yield same joy as graduation at a physical ceremony in the presence of family, friends and fellow graduates.

In many African cultures, and specifically in Zimbabwe, visiting the sick in hospital or at home and attending burial ceremonies of the departed is almost a social obligation. Unfortunately, the social values were obligated by limitations of travel caused failure to bury loved ones according to most of respondents. The respondents indicated that as a people they gather for funerals consoling one another which they were not able to freely do in fear of the virus and the restrictions placed. During the early day of lockdown in March, the government reduced the number of visitors per patient in hospitals. As lockdown rules tightened, the number of visitors and visits per day were further reduced, disallowing most willing individuals from taking part. Even those from the patient's religious groups could only render support remotely without visiting their colleagues. One of the respondents who was once admitted in hospital during the lockdown period felt detached from the rest of the world as most of the relatives and friends were not allowed to visit.

\subsection{Psychological Impacts}

According to respondents, the Covid-19 pandemic triggered feeling of fear and uncertainty among the citizens. This included the fear and stress due to possibility of getting infected given the destructive nature of the virus while there is no cure of it. The other impact was the stress due to the unpredictable nature of the virus. Most citizens once believed that the virus affects those with contact with returnees from countries where infection levels were high. 
Respondents indicated that it was stressful to notice that some infected citizens had no travel history or contact with returnees. This included infections registered in isolated environments such as prisons while the country was on lockdown. Another respondent indicated that fear and shock come from "just not knowing what's next in my life or family's life is very traumatising". Additionally, the first cases in Zimbabwe were recorded in March in the hot-wet season. There is a strong belief in the citizens that the virus manoeuvres the worst under cool conditions. Based on responses obtained, approaching of the cool dry season is another cause of worry and fear among most seasons. Others highlighted that fear has engulfed many citizens to the extent of not grabbing opportunities that were brought by the pandemic.

Other respondents have indicated great loss of hope due to the pandemic. They are affected me by hearing on and seeing on news that thousands are hospitalised with others dying every day. Hope is lost for some after comparing the economic status and health facilities in the so far most impacted countries with the situation is Zimbabwe. The thought that United States of America, Italy and China are failing to handle the pandemic pushes the impression that if the virus spreads wide in Zimbabwe would results in even worse predicaments. The absence of a vaccine for the virus gives others the impression that once infected there will be no chance of survival. The effects are worse traumatizing when one imagines that "I will be the next". The first case in Zimbabwe affected a member from a perceived wealthy background which gives impression that it will be worse for the low income strata. However, others indicated that records of recovered patients stand as a source of hope and inspiration that infection with the virus does not always result in loss of life.

Lockdown rules in some places were enforced by members of the uniformed forces to ensure that citizens cooperate. This, according to some responses, made the country appear like a war zone which traumatized citizens. Being forced to stay indoors away from usual errands made other respondents to feel like caged or imprisoned. This in some cases led to boredom caused by the stress of being separated from relatives and friends. For people whose professions involve interacting with people, staying indoors deprived them of that commitment and mentally tortured them. The loss of income due to limited business activities resulted in stress as some citizens failed to service debt amidst rising cost of living. "Balancing family needs against zero income" was cited as stressful by one of the respondents. Besides the social responsibility aspect of it, not visiting the sick and restriction regarding burial of the deceased also led to mental displeasure. Psychological discomforts also resulted from postponement of most pre-planned projects after investing a lot of time into them. Feeling of grief resulted from complete failure of projects or in other cases from forced inability to achieve set targets within time frames owing to the pandemic. The impact, to some, came at a time when projects were nearing completion the thought of which became a heavy psychological burden.

A feeling of insecurity was also fostered by the pandemic. Insecurities include those arising from the feeling that local hospitals are not adequately equipped. The other contributed raised was from erosion of savings and income which makes most citizens to feel exposed and highly dependent on the government, an external factor outside their control. University and 
college students also felt insecure about the future beyond the pandemic. One of the students was "very stressed of what will be of tomorrow if this pandemic continues". The students felt unsure whether they will be able to finish their courses. The future seemed uncertain considering that their base of income was low while those on industrial attachment felt allowance were swept by inflation becoming too little to be withdrawn from the bank under the current situation.

\subsection{Effect on Traditional/Religious Values}

During the early stages of restrictions, religious denominations were allowed to gather as normal, later on smaller groups were allowed until the full lockdown period when the gatherings were completely banned. This, according to most respondents from different religious groups, made the Covid-19 pandemic unique. In the case of other challenges, participation of religious groups used to be encouraged as it provided believers with supernatural strength and comfort. Such believers felt shut out by the restrictions as their major sources of strength and inspiration were closed down. Closure of religious gatherings also deprived members of the denominations of much needed support such as counselling services during the lockdown period. One of the responses expressed concern that weak members may lose track due to absence of gatherings where they strengthen each other in faith and are guided by denomination leaders.

Besides the banned gathering, other religions were further hammered by restrictions of movement which prohibited home visits. In other cases where permitted distances could be travelled some of the members were not welcoming in fear of contracting the virus. Religious valuables such as expression of brotherly love and greeting through hugs and handshakes were no longer possible under efforts to control spread of corona virus. Other respondents benefited from the lockdown such by getting more time to introspect on spiritual values. It gave some opportunity to demonstrate Godly love to victims and affected people. The period made others to realize that religion is a way of life which must proceed even without gatherings when necessary. There were also respondents who sounded unmoved by the pandemic even in the background of rising number of infections due to solid faith in their religion. One such respondents mentioned that "There is nothing new. I am a firm believer in Christ. These things will come to pass". The pandemic made others "more alert to immorality"

\section{Suggestions on Handling of Covid-19 Related Social Impacts}

A number of responses indicated that government and partners must provide for vulnerable populations to cushion them from the losses and rising cost of living. Currently available assistance was offered mostly to the elderly while respondents felt that some unemployed young people and child headed families may also need similar assistance. Students on tertiary education need post-Covid-19 financial support or fees remissions to avoid many dropouts as a result of economic hardships due to the pandemic. Other respondents gave sentiment that the government should provide resources to run more tests and conduct proper research on the cause, transmission and treatment of the disease. There were also feelings that information about the pandemic must be shared in all areas rather than concentrating in urban 
areas while leaving the rural dwellers vulnerable. It was raised that the affected and infected need to be supported spiritually, psychologically and with basic need such as food to take them through the tough phase rather than stigmatization. Spreading messages of hope will restore peace, including showing empathy to the most vulnerable. As much as experts talk about social distancing and practicing high hygiene, it was suggested that they must also talk about safe ways of relating with those who have recovered.

At the peak of the lockdown prices of data bundles increased exponentially to levels where most of the ordinary citizens in the country could not afford. In order to enhancing sharing of and access to information, mobile and telecommunication companies should significantly have lowered tariffs instead. This was also going to help to "bridge the social gap created by Covid-19 related stringent measures" and reduce temptations of disobeying movement restriction. The cost of living continued to rise to the detriment of the unemployed and low income strata leading to opinion that price control and anti-inflationary measures needed to be enforced to protect ordinary citizens. While some people need financial help to recover from the effects of this pandemic, there are also others who need nonmonetary support such as counselling due to the traumatic nature of the pandemic. The government announced that citizens could pay rentals in instalments to cushion them from pressure due to income loss and this was applauded by most respondents. In the same vein, views were expressed that similar arrangement was needed in the payment of bills such as electricity and water especially for those who work in the informal sector. Most ordinary citizens were increasingly finding it difficult to put food on the table while bills were exerting additional pressure on them. The number of public buses needs to be increased to enable people to observe social distancing rules. Supplies of basic commodities in shops must also be increased to avoid long queue and breaking of rules in attempt to grab scarce commodities.

\section{Discussion of Findings}

The pandemic mostly caused loss of income at different levels of the economy disruptions globally (Goodell, 2020). The economic pressures triggered by restricted and banned movement of people and goods were felt by different levels of communities in Zimbabwe. During the lockdown period, businesses lost income, governments lost revenue while citizens had losses which included reduced income and loss of savings. In Zimbabwe, a sudden rise in demand for basic groceries resulted in price hikes which severely threatened lives of low income strata. The situation was worsened by instability of exchange rates which reduced the value of the local currency making most basic goods and services unaffordable to a significant proportion of citizens. The lockdown period reduced production levels of most industries which were not even operating at their full capacity before the pandemic. As a result of reduced income, some companies resorted to reduction of employee salaries or other means of cutting employment costs (such as retrenchment) which strained affected citizens under rising cost of living. However, based on responses, although losses were huge, other individuals and sectors registered gains in income due to the pandemic. Although this was not investigated, based on expert knowledge and experience, this could business that trade in Covid-19 related products or in basic commodities whose demand increased due to stocking. In Singapore, announcement of lockdown rules also triggered panic buying of until stores ran 
out of supply (Ho et al., 2020). Cao et al., (2020) and Torales et al., (2020) observed that impacts of the pandemic on the economy were among causes of recorded psychological challenges.

The lockdown and pandemic environment caused fear, stress and trauma, uncertainty and loss of hope in some citizens in Zimbabwe. The loss of hope and uncertainty in some cases was caused by impact of the virus on countries with stable economies such as United States of America given the current economic situation in the country. Due to the economic hardships affecting the nation, some citizens even doubted level of preparedness and capacity of local hospitals to manage the pandemic. In China, the virus has also caused psychological pressures which include fear, anxiety, depression and high rate of use of hazardous and harmful alcohol (Ahmed et al., 2020; Cao et al., 2020; Zhang, 2020; Zheng, 2020). Zhang (2020) observed that research participants in Liaoning Province of China reflected mild stressful impacts due to the pandemic. Due to impact of the pandemic on mental wellness of citizens in China, the National Health Commission promoted the use of online psychological interventions. Similarly, in Singapore, psychological support and public addresses were used to help citizens through the mental torture (Ho et al., 2020). According to Ho et al., (2020), the levels of fear in Singapore were greater than of 17 years ago when the SARS virus. Psychological pressures were also reported in health practitioners who were on the frontline of fight against the pandemic (Ahmed et al., 2020; Shaw, 2020). According to Shaw (2020) this caused a feeling of helplessness among the nurses.

Besides the physical health effects, hospitalised citizens (even due to other illnesses) experienced mental torture during the pandemic period. Experiences included being suspected or labelled of infection by the virus by other members of the community resulting in stigma and trauma. In Zimbabwe, restrictions on number of daily visitors and visits per patient in hospital further traumatised both the patients and their relatives and friends. There is social value and connectedness in visiting the sick either in hospitals or even at their homes all of which were minimized by lockdown rules. This is in tandem with observation by Li et al., (2020) that people were more concerned about families and friends than leisure during the restrictions period. Isolation in new environments in hospitals lead to increased stress and behavioural problems (Wang et al., 2020). This explains the concerns raised by the patients and their relatives in response to banning and limiting of visits to the hospitals. The other source of stress was the effect of lockdown in contravening with traditional values in terms of burial of the deceased. The deceased's bodies were handled in manner prescribed by the government while size of gatherings were also limited depriving most citizens of the freedom to bid farewell to their departed loved ones.

A feeling of isolation and emptiness also resulted from banning of religious gatherings although this was good for managing the spread of the virus. Spending a long time indoors without physically attending religious gatherings deprived citizens of moral and other supports. The deepened psychological pressures which could not be relieved without interaction with other members of the same faith. According to World Health Organization (2020), faith based organisations provide support which includes advocating for the rights of the vulnerable groups, providing comfort and being trusted as a source of information. In 
Zimbabwe, some of the faith based organizations donated food and other basic necessities (through the government and directly) to vulnerable communities. Their role in sharing information was limited by lockdown rules although others resorted to use of social media to remain connected to their members. On the use of social media, hike in data bundles experienced in Zimbabwe hammered information sharing and access by most citizens. However, other network providers offered cheaper options to faith based organisations with membership of a certain size.

Communication mechanism used were viewed by some respondents as not considering the rural and remote yet among the most vulnerable. Experiences from Singapore countries indicated that awareness by experts, public address of citizens and regular updates relieved the citizens of some panic, doubt, fear and pressure (Ho et al., 2020). Magnitude of uncertainty and fear was high until the Prime Minister re-assured the nation of measures in place to ensure their safety. Therefore, spreading messages of hope have potential to heal citizens of psychological distress. The current communication mechanisms such as television and radio may not be effective especially in most rural and remote areas where either signal reception is poor communities have no receivers.

\section{Recommendations}

The study recommends methods of transmitting information need to be improved to include platforms accessible to citizens in rural and remote areas. There is also need to engage faith based organisations to fight psycho-social impacts of the pandemic through supports which include spreading message of hope and boosting donations for vulnerable groups. Training and awareness raising is needed to help citizens to fight the virus as well as associated stigma. The potential of periodic relaxation of lockdown rules to allow brief moments of social interactions (while maintaining social distancing) to reduce psychological distress needs to be tested.

\section{Conclusion}

The study used qualitative and quantitative approaches to investigate the psychosocial impact of the Covid-19 pandemic on communities in Zimbabwe. An online survey was carried out with most of the responses received from Harare which is the epicentre of infections in the country as at early June 2020. Based on findings, the study concluded that the pandemic negatively affected different levels of economic activities and psychosocial wellness in the country. Some of the economic losses will take time to recover from as citizens ended up using savings which were ear marked for other aspects of development. Prices of basic commodities increased while the local currency lost value further burdening the low income strata. Psychological pressures were mostly in the form of fear, feeling of uncertainty, loss of hope and depression. The pressure were worsened by social isolation due to restrictions in movement and gatherings which were imposed by the government as well as other countries during the period. The banning of gatherings of faith based organizations deprived citizens of social and psychological supports at a time they were needed the most. The communication methods of virus information could be insufficient to cover all levels of communities especially in rural and remote areas. 


\section{References}

Ahmed, Z., Ahmed, O., Aibao, Z., Hanbin, S., Siyu, L., \& Ahmad, A. (2020). Epidemic of COVID-19 in China and associated Psychological Problems. Asian Journal of Psychiatry, 51(April), 102092. https://doi.org/10.1016/j.ajp.2020.102092

Cao, W., Fang, Z., Hou, G., Han, M., Xu, X., \& Dong, J. (2020). The psychological impact of the COVID-19 epidemic on college students in China. Psychiatry Research, 287(March), 112934. https://doi.org/10.1016/j.psychres.2020.112934

CDC COVID-19 Response Team. (2020). Severe Outcomes Among Patients with Coronavirus Disease 2019 ( COVID-19 ) — United States , February 12 - March 16 , 2020. Morbidity and Mortality Weekly Report, 69. https://doi.org/10.15585/mmwr.mm6912e2

Dong, E., Du, H., \& Gardner, L. (2020). Open access epidemiological data from the COVID-19 outbreak A family cluster of SARS-CoV-2 infection involving 11 patients in Nanjing, China Outbreak investigation for COVID-19 in northern Vietnam. The Lancet Infectious Diseases, 20(5), 534-535. https://doi.org/10.1016/S1473-3099(20)30147-X

Flahault, A. (2020). COVID-19 cacophony: is there any orchestra conductor? Future of Chernobyl research: the urgency for consolidated action. The Lancet, 395(10229), 1037. https://doi.org/10.1016/S0140-6736(20)30491-8

Gao, J., Tian, Z., \& Yang, X. (2020). Breakthrough: Chloroquine phosphate has shown apparent efficacy in treatment of COVID-19 associated pneumonia in clinical studies. 1-2. https://doi.org/10.5582/bst.2020.01047

Goodell, J. W. (2020). COVID-19 and finance: Agendas for future research. Finance Research, (March). https://doi.org/10.1016/j.frl.2020.101512

Hellewell, J. (2020). Comment Deciphering the power of isolation in controlling COVID-19 outbreaks. 452-453. https://doi.org/10.1016/S2214-109X(20)30085-1

Ho, C. S. H., Chee, C. Y. I., Psychiatry, M., \& Ho, R. C. M. (2020). Mental Health Strategies to Combat the Psychological Impact of COVID-19 Beyond Paranoia and Panic. Commentary.

Lau, H., Khosrawipour, V., Kocbach, P., Mikolajczyk, A., Schubert, J., Bania, J., \& Khosrawipour, T. (2020). The positive impact of lockdown in Wuhan on containing the COVID-19 outbreak in China. (March), 1-7. https://doi.org/10.1093/jtm/taaa037

Li, S., Wang, Y., Xue, J., Zhao, N., \& Zhu, T. (2020). The Impact of COVID-19 Epidemic Declaration on Psychological Consequences : A Study on Active Weibo Users. International Journal of Environmental Research and Public Health, 17, 2032.

Qiu, Y., Chen, X., \& Shi, W. (2020). Impacts of social and economic factors on the transmission of coronavirus disease 2019 ( COVID-19) in China. https://doi.org/10.1101/2020.03.13.20035238

Remuzzi, A., \& Remuzzi, G. (2020). Health Policy COVID-19 and Italy : what next? The Lancet, 395(10231), 1225-1228. https://doi.org/10.1016/S0140-6736(20)30627-9 


\section{Macrothink}

Journal of Public Administration and Governance ISSN 2161-7104 2020, Vol. 10, No. 3

Shaw, S. C. K. (2020). Nurse Education in Practice Hopelessness, helplessness and resilience : The importance of safeguarding our trainees' mental. Nurse Education in Practice, 44(March), 102780. https://doi.org/10.1016/j.nepr.2020.102780

Singh, R., \& Adhikari, R. (2020). Age-structured impact of social distancing on the COVID-19 epidemic in India. ArXiv, 1-9.

Torales, J., Higgins, M. O., Castaldelli-maia, J. M., \& Ventriglio, A. (2020). The outbreak of COVID-19 coronavirus and its impact on global mental health. 3-6. https://doi.org/10.1177/0020764020915212

Wang, H., Li, T., Barbarino, P., Gauthier, S., Brodaty, H., Weidner, W., \& Yu, X. (2020). No time for dilemma : mass gatherings must be suspended. The Lancet, 395(10231), 1191-1192. https://doi.org/10.1016/S0140-6736(20)30754-6

World Health Organization. (2020). Coronavirus disease 2019 (COVID-19). Situation Report, 80(April).

Zhang, Y. (2020). Impact of the COVID-19 Pandemic on Mental Health and Quality of Life among Local Residents in Liaoning Province, China: A Cross-Sectional Study. https://doi.org/10.3390/ijerph17072381

Zheng, W. (2020). Mental health and a novel coronavirus (2019-nCoV) in China. Journal of Affective Disorders, 269, 201-202. https://doi.org/10.1016/j.jad.2020.03.041

Zimbabwe National Statistics Agency. (2017). Inter-censal demographic survey. Zimbabwe National Statistics Agency.

\section{Copyright Disclaimer}

Copyright for this article is retained by the author(s), with first publication rights granted to the journal.

This is an open-access article distributed under the terms and conditions of the Creative Commons Attribution license (http://creativecommons.org/licenses/by/4.0/). 